\title{
Internet and people with intellectual disability: an approach to caregivers' concerns, prevention strategies and training needs
}

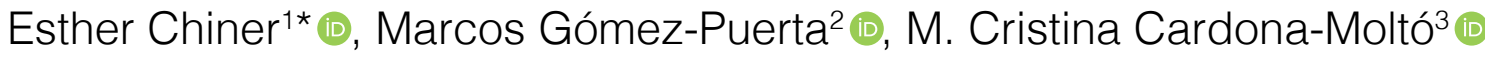 \\ 'Department of Health Psychology, University of Alicante, Spain \{esther.chiner@ua.es\} \\ 2Department of Developmental Psychology and Teaching, University of Alicante, Spain \{marcos.gomez@ua.es\} \\ 3Department of Health Psychology, University of Alicante, Spain \{cristina.cardona@ua.es\}
}

Received on 28 March 2017; revised on 24 May 2016; accepted on 29 May 2017; published on 15 July 2017

DOI: 10.7821/naer.2017.7.243

(cc) BY-NC-ND

\begin{abstract}
The aim of this study was to explore caregivers' views about the risks of the Internet for people with intellectual disabilities and their preparation and ability to use prevention strategies to address them. The participants (20 family members and 24 staff members) belonged to a non-profit association working with people with developmental and intellectual disabilities and were asked to respond to a questionnaire about Internet safety and risks. Findings show some concerns from caregivers with regard to the use of the Internet by people with intellectual disabilities and suggest that this group is more vulnerable to online risks. Participants use different kinds of strategies to prevent the risks but they have not received any formal training. They think that this training should come from the Administration and other organisations. Some differences were found between family and staff members' responses. Training programmes for all the groups involved in this process (i.e. people with intellectual disabilities, staff and family members) should be designed, implemented and assessed to promote the inclusion of people with intellectual disabilities in the digital arena.
\end{abstract}

KEYWORDS: INTELLECTUAL DISABILITY, INTERNET, SAFETY, FAMILY, PROFESSIONAL STAFF

\section{INTRODUCTION}

In the last few decades, there have been significant changes in how people see individuals with intellectual disabilities (ID). Initially, they were perceived as being ill and difficult to integrate into society, whereas nowadays they are seen as full citizens. Thus, it has been possible to move, not without difficulty, from exclusion to integration and subsequently, to inclusion.

We understand inclusion as the strategy to increase the participation of these people at school and in the community, which therefore reduces their exclusion or discrimination. Although at first the development of inclusion was concentrated at schools, it has progressively been extended to other contexts such as work, leisure or information and communication technologies (ICT). Regarding ICTs, in the late 1970s the concept of a digital divide

*To whom correspondence should be addressed:

Departamento de Psicología de la Salud

Universidad de Alicante

Campus de Sant Vicent del Raspeig

Ap. 99 E-03080 Alicante, Spain was defined as the differences identified in the use of computer tools between developed and underdeveloped countries. Subsequently, this concept was also applied for Internet use, initially referred specifically to problems related to the lack of computer equipment or connectivity and, later, to the lack of skills and abilities that are necessary for the use of this technology. In order to alleviate the digital divide caused by this lack of skills that hindered the use of the Internet by some groups, digital literacy plans were designed and implemented. These training actions were directed especially to groups at risk of digital exclusion (e.g. elderly or uneducated persons) in order to limit this technological gap and thus increase their participation in the information society. This process was particularly relevant considering that digital illiteracy was a subtle but effective form of social exclusion, limiting the participation of certain groups in socially valuable resources (Pantoja, Orellana, Muñoz, \& Espiñeira, 2012). Recent research in the Spanish context has identified a number of characteristics that appear to be related to a greater tendency towards discrimination in ICTs such as age, income level, educational level, or the presence of a disability (Orange Foundation, 2013). Moreover, among the group of people with disabilities, those with intellectual disabilities are the ones with the greatest digital exclusion (Valero, Vadillo, Herradón, Bermejo, \& Conde, 2011), despite them showing positive attitudes towards the use of ICTs (Auna Foundation, 2004). However, although there is still a significant difference with respect to the population without disabilities, there has been an increasing use of the Internet by people with ID (Feng, Lazar, Kumin, \& Ozok, 2008).

Internet access offers multiple benefits to people with ID such as learning, social interaction and the participation in mutual support groups (Molin, Sorbring, \& Löfgren-Martenson, 2015). Consequently, access to the Internet has been promoted from associations, schools and from their own homes as an important and necessary environment for them to participate in the current information and communication society. However, potential risks have also been identified for those who are perceived as especially vulnerable to abuse, such as people with ID (Chadwick \& Wesson, 2016). Some of the identified risks in the use of the Internet are unwanted contacts (e.g. grooming, sexual harassment, cyberbullying, or abuse of personal and private information), or inappropriate behaviour of the individual with ID (e.g. insulting or threatening others) (Livingstone \& Haddon, 2009). This perception of susceptibility to abuse stems from the ingenuity and credulity that inherently characterise the social behaviour of 
people with ID (Luckasson et al., 2002). In this sense, a recent study carried out in the Spanish context by Salmerón, Gómez and Fajardo (2016) with 40 students with intellectual disability showed a tendency to believe the information offered in Internet forums without identifying the reliability and trustworthiness of the source of information, which differed from the control groups without intellectual disability.

It has been also verified the existence of prejudices towards people with ID and their behaviour (World Health Organization, 2011); these prejudices have also been identified with regard to online risks. The study conducted by Chadwick, Quinn and Fullwood (2017) surveyed 166 people without disabilities about the benefits and the risks of Internet use by themselves and by people with ID. Results showed that online benefits and risks were perceived greater for people with ID than for the general population. The most relevant risks identified were cyberbullying, providing too much personal information to others, and accessing misleading advertising. However, this research focused its interest on the general population, and did not collect the perceptions of the immediate environment of people with ID.

The training and the supports that people with ID receive are key to promoting Internet access. Many researchers have emphasised the importance of offering individualised support to people with ID (e.g. Kydland, Molka-Danielsen, \& Balandin, 2012; Näslund \& Gardelli, 2013). Within these supports, the most important are those provided by their caregivers, that is, from family members and professionals from different support services for people with ID (e.g. schools, associations, vocational training centres, and sheltered work centres). In this sense, the perception that caregivers have about the risks of using the Internet by people with ID modulate, to a certain extent, online access. If caregivers perceive that individuals with ID may face certain risks that they will not know how to handle, they may provide them less opportunity for online access (Chadwick \& Wesson, 2016). In fact, the research carried out by Seale (2003) found evidence that caregivers made decisions about what online contents were considered safe for people with ID. Moreover, the mere provision of ICT resources for training and support at households or at organisations does not solve these difficulties on its own. Caregivers' beliefs and prejudices are psychological barriers that condition the use of the Internet by people with ID and these barriers are resistant to change (Parsons, Daniels, Porter, \& Robertson, 2008). In fact, Seale, Nind and Simmons (2013) consider that caregivers' perceptions of vulnerability and risk management are determinants to provide the supports that people with ID need to gain online access.

In this regard, the "positive risk taking" approach (Jay, 1979; Perske, 1972) promotes the identification and a positive management of the risks, assuming that risks are part of the daily life of any human being and are necessary for their development and growth. In this sense, a shared decision-making process is established in which the subject and his or her caregiver jointly decide on the risks and actions to be performed (McConkey \& Smyth, 2003). This approach could be a good intervention and risk management strategy for people with ID (Seale, 2014); however, the study conducted by Clarke, Lhussier, Minto, Gibb and Perini (2005) revealed that caregivers and people with disabilities can present different perceptions of risks and therefore make it difficult to make shared decisions. It is important to note that there is still not enough scientific evidence about the effectiveness of this perspective in online risk management for people with ID.

Research in the field of the use of ICT by people with ID has focused on the educational potential of using new technologies, the patterns in its use and the factors that condition the access and use of such technologies (Seale et al., 2013). However, few studies have focused on the analysis of the perceptions of caregivers (i.e. family and staff members) about the risks associated with the use of the Internet by people with ID and their training for the implementation of prevention strategies and risk management. Our research tried to respond to this circumstance by exploring caregivers' concerns and views about these issues. The study also aimed to determine differences between family and staff members' perceptions. Particularly, the study was designed to examine the following research questions:

(1) How safe do caregivers perceive the Internet to be?

(2) Which are caregivers' major concerns about the use of the Internet by people with ID?

(3) Which strategies do caregivers use to prevent risks on the Internet?

(4) How prepared do caregivers feel to guarantee Internet safety? In addition, which sources of information and training do they use and prefer to learn about Internet safety?

\section{METHODOLOGY}

\subsection{Participants}

A convenience sample of 44 caregivers ( 20 family members and 24 staff members) participated in this study. Eighteen participants $(42 \%)$ were male and 25 were female $(58 \%)$ and their age ranged between 26 and $85(M=48 ; S D=12.2)$. All of them belonged to an association in the province of Alicante, Spain, which provides comprehensive support to people with developmental and intellectual disabilities. This non-profit organisation offers a variety of services (e.g. early intervention, vocational training, sheltered work, leisure) in order to improve the quality of life of people with ID. The average of working experience in the association of the staff members was 13.11 years $(S D=8.47)$, ranging from one to 28 years.

Eighty-two percent of the participants $(n=36)$ used the Internet every day, $9 \%(n=4)$ used it once or twice per week and $5 \%$ used it once or twice per month. Only two participants (4\%), both of them family members, never used the Internet at all.

Given the size of the sample and the fact that all participants belonged to the same organisation, the study does not allow generalising of the results and it is unknown whether the sample is representative of the wider population. However, the study provides a good first approach to the main concerns and needs of caregivers with regard to Internet safety and use by people with ID. This work should be considered as the starting point of other studies with more representative samples.

\section{$2.2 \quad$ Instruments}

The questionnaire Use, Risks, and Safety on the Internet of People with Intellectual Disabilities was designed for this study. It was developed using the European network EU Kids Online as a framework (Garmendia, Garitaonandia, \& Casado, 2011). In order to adapt the instrument to the two groups participating in the study, two versions were prepared. Differences between versions included the writing style and the information included in the demographic data section. The questionnaire was comprised of five sections: (a) Demographic data, (b) Internet safety, (c) Internet risks and concerns for people with ID, (d) Prevention strategies, and (e) Preparation and information on Internet safety (e.g. strategies used, information or training source). Participants had to 
respond to multiple choice, dichotomous (yes and no) and fourpoint Likert-type scales (e.g. $1=$ Not safe, $2=$ Somewhat safe, $3=$ Quite safe, 4 = Very safe)

The instrument was assessed by a panel of experts $(n=11)$ obtaining a content validity index (CVI) of 1 for the family members' version and a CVI of .98 for the professionals' version (Lawshe, 1975).

\subsection{Procedure}

A non-experimental quantitative study was conducted, using a cross-sectional survey design. Questionnaires were handed out personally to the staff members of the association and were sent by postal mail to the family members. Participants were asked to complete the instrument and return it to the association within two weeks. The instrument included a cover letter informing about the purpose of the study and its relevance, and participants were asked to give their written consent.

Expecting a low response rate, a convenience sampling procedure was chosen to reach most of the population. However, the response rate was still low. In the case of staff members, $56 \%$ of the questionnaires were returned, but only $14 \%$ of the family members completed the survey. In addition, 16 questionnaires were removed since they were incomplete.

\subsection{Data analysis}

Descriptive analyses were carried out to explore the data collected (e.g. means, standard deviations and percentages). Differences between staff and family members were examined using the Mann-Whitney U test for Likert-type scales and the phi coefficient for dichotomous responses. Differences were considered significant at the .05 level $(p<.05)$.

\section{RESULTS}

\subsection{Caregivers' perceptions about Internet safety}

As shown in Table 1, 66\% $(n=29)$ of the participants considered that the Internet is safe for adults without ID. However, when it refers to adults with ID, most of the respondents $(91 \%, n=40)$ thought that the Internet is not safe. Likewise, all of the participants considered that the Internet is slightly safe or even not safe at all for minors with and without ID. Differences between family and staff members, using the Mann-Whitney U test, were not found $(p>.05)$.

\subsection{Caregivers' concerns about the use of the Internet by people with ID}

Participants were especially worried about someone using the personal information of the individual with ID without his or her consent $(66 \%, n=29)$ or being asked for information or photos
$(64 \%, n=28)$. They were also concerned about people with ID receiving sexual photos or videos that they do not want to see $(61 \%, n=27)$, being threatened $(59 \%, n=26)$ or someone telling others unpleasant things about them $(50 \%, n=22)$. A lower proportion of the participants were worried about questions such as losing money online $(48 \%, n=21)$, others wanting to meet people with ID against their will $(45 \%, n=20)$ and other people using their password to impersonate them $(43 \%, n=19)$. On the other hand, situations like being blocked on an online group or activity $(80 \%, n=35)$ or someone trying to flirt with them against their will $(63 \%, n=28)$ were not perceived as a big concern. Details are displayed in Table 2.

Differences between family and staff members were found in four items. First, regarding the concern 'someone trying to flirt with people with ID against their will' $(Z=2.386, p=.017)$, family members were much less worried than the staff members were $(85 \%$ vs $46 \%)$. Second, with respect to the item 'someone asking them for information or photos' $(Z=3.081, p=.002), 65 \%$ of the participant family members were little or not worried at all, while only $12 \%$ of the staff members felt this way. Third, only $25 \%$ of the family members were worried about 'someone wanting to meet people with ID against their will' versus $63 \%$ of the staff members $(Z=3.081, p=.005)$. Finally, while $79 \%$ of the staff members were worried about the person with ID receiving sexual photos or videos, only $60 \%$ of the family members were only somewhat worried or not worried at all $(Z=2.134, p=.033)$.

\subsection{Caregivers' use of prevention strategies}

Table 3 shows the strategies most commonly used by caregivers to prevent risks on the Internet for people with ID. The strategy mostly used is talking with them about what they have done on the Internet (84\%), followed by talking about the risks of online chatting or flirting with strangers $(72 \%)$. Other strategies that are commonly used are (a) warning people with ID about misleading advertising $(69 \%)$, (b) talking with them about the risks of identity and data theft (62\%), and (c) telling them which webpages are appropriate and which are not $(61 \%)$. Other strategies less frequently used are installing programs to prevent spam and virus (44\%), warning people with ID about different kind of swindles and phone charges $(41 \%)$, controlling the time they spend online $(35 \%)$, checking the history of visited webpages $(31 \%)$ and controlling the use of social networks (31\%), among others. Moreover, only $21 \%$ of the participants sit next to the individuals with ID when they go online, activate content control filters, and install navigating and access control programs to certain webpages. Eighteen percent of the participants had shared activities on the Internet with individuals with ID, had forbidden them sharing information on the Internet and had checked new friends and contacts on their social network profiles. Finally, only $8 \%$ of the respondents have ever forbidden the use of social networks to the person with ID.

Table 1. Caregivers' perceptions about Internet safety

\begin{tabular}{lcccccccc}
\cline { 2 - 7 } & \multicolumn{2}{c}{ Not at all safe } & Somewhat safe & \multicolumn{2}{c}{ Quite safe } & \multicolumn{2}{c}{ Very safe } \\
\cline { 2 - 8 } & $n$ & $\%$ & $n$ & $\%$ & $n$ & $\%$ & $n$ & $\%$ \\
\hline Internet for adults without ID & 3 & 7 & 12 & 27 & 27 & 61 & 2 & 5 \\
Internet for adults with ID & 16 & 36 & 24 & 55 & 4 & 9 & & \\
Internet for minors without ID & 20 & 45 & 24 & 55 & & & & \\
Internet for minors with ID & 32 & 73 & 12 & 27 & & & \\
\hline
\end{tabular}


Table 2. Caregivers' concerns about the use of the Internet by people with ID

\begin{tabular}{|c|c|c|c|c|c|c|c|c|}
\hline \multirow[b]{2}{*}{ Concern } & \multicolumn{2}{|c|}{$\begin{array}{c}\text { Not at all } \\
\text { worried }\end{array}$} & \multicolumn{2}{|c|}{$\begin{array}{l}\text { Somewhat } \\
\text { worried }\end{array}$} & \multicolumn{2}{|c|}{ Quite worried } & \multicolumn{2}{|c|}{ Very worried } \\
\hline & $n$ & $\%$ & $n$ & $\%$ & $n$ & $\%$ & $n$ & $\%$ \\
\hline 1. Other people trying to flirt with them against their will & 12 & 27 & 16 & 36 & 10 & 23 & 6 & 14 \\
\hline 2. Other people asking them for information or photos & 7 & 16 & 9 & 20 & 17 & 39 & 11 & 25 \\
\hline 3. Other people wanting to meet them against their will & 11 & 25 & 13 & 30 & 8 & 18 & 12 & 27 \\
\hline 4. Being insulted by the Internet & 8 & 18 & 17 & 39 & 13 & 29 & 6 & 14 \\
\hline 5. Other people telling others unpleasant things about them & 7 & 16 & 15 & 34 & 18 & 41 & 4 & 9 \\
\hline 6. Being blocked on an online group or activity & 18 & 41 & 17 & 39 & 7 & 16 & 2 & 4 \\
\hline 7. Being threatened online & 7 & 16 & 11 & 25 & 17 & 39 & 9 & 20 \\
\hline 8. Receiving sexual photos or videos that they do not want to see & 6 & 14 & 11 & 25 & 17 & 38 & 10 & 23 \\
\hline 9. Other people trying to sell them things that they do not want & 12 & 27 & 15 & 34 & 10 & 23 & 7 & 16 \\
\hline $\begin{array}{l}\text { 10. Other people using their personal information without their } \\
\text { consent }\end{array}$ & 7 & 16 & 8 & 18 & 17 & 39 & 12 & 27 \\
\hline 11. Losing money online & 16 & 36 & 7 & 16 & 13 & 30 & 8 & 18 \\
\hline 12. Other people using their password to impersonate them & 14 & 32 & 11 & 25 & 13 & 29 & 6 & 14 \\
\hline
\end{tabular}

Table 3. Prevention strategies used by caregivers to prevent risks on the Internet for people with ID $(N=39)$

\begin{tabular}{|c|c|c|}
\hline Prevention strategies & $n$ & $\%$ \\
\hline 1. To talk with them about what they do on the Internet & 32 & 84 \\
\hline 2. To talk with them about the risks of online chatting or flirting with strangers & 28 & 72 \\
\hline 3. To talk with them about misleading adverstising & 27 & 69 \\
\hline 4. To talk with them about the risks of identity/data theft & 24 & 62 \\
\hline 5. To talk with them about which webpages are appropriate and which not & 24 & 61 \\
\hline 6. To install programs to prevent spam and virus & 17 & 44 \\
\hline 7. To talk with them about what they would do in case of feeling upset or worried about something & 16 & 41 \\
\hline 8. To talk with them about different kinds of swindles and phone charges & 7 & 41 \\
\hline 9. To control the time they spend online & 14 & 36 \\
\hline 10. To check the history of visited webpages & 12 & 31 \\
\hline 11. To control the use of social networks & 12 & 31 \\
\hline 12. To stay around while they go online & 11 & 28 \\
\hline 13. To put the computer in common areas at home & 10 & 26 \\
\hline 14. To allow them the use of mobile devices only in common areas & 10 & 26 \\
\hline 15. To check the emails, whatsapp messages, etc. & 10 & 26 \\
\hline 16. To sit next to them when they go online & 8 & 21 \\
\hline 17. To activate content control filter & 8 & 21 \\
\hline 18. To install navigating and access control programs to certain webpages & 8 & 21 \\
\hline 19. To share with them activities on the Internet & 7 & 18 \\
\hline 20. To forbid them sharing information on the Internet & 7 & 18 \\
\hline 21. To check new friends and contacts added on their social networks profiles & 7 & 18 \\
\hline 22. To forbid the use of social networks & 3 & 8 \\
\hline 23. Not used any strategy & 5 & 13 \\
\hline
\end{tabular}


Significant differences were found between family and staff members in only one strategy: forbidding the person with ID to share information on the Internet $(\phi=.391, p=.013)$. Family members use this strategy more frequently $(35 \%)$ than staff members $(5 \%)$.

\subsection{Information and training in Internet safety}

With regard to caregivers' training level, only $43 \%$ of the participants think that they are trained to prevent problems, but almost half of them $(48 \%)$ think that they are prepared to cope with problems or solve them. No significant differences were found between family and staff members.

Participants were also asked about what information sources they use with respect to Internet safety as well as from which sources they would prefer to receive information about this issue. Table 4 displays their responses to both questions. Results show that caregivers got the information about Internet safety mostly from media such as TV, radio or newspapers $(55 \%)$ and in a lower proportion from family and friends (37\%). Some learned about this issue from non-profit organisations $(25 \%)$ and specialised webpages $(28 \%)$, and very few from their Internet supplier and the Administration (12\%).

Table 4. Sources of information about Internet safety $(N=40)$

\begin{tabular}{lcccc}
\hline \multirow{2}{*}{\multicolumn{1}{c}{ Information sources }} & \multicolumn{2}{c}{ Used } & \multicolumn{2}{c}{ Preferred } \\
\cline { 2 - 6 } & $n$ & $\%$ & $n$ & $\%$ \\
\hline $\begin{array}{l}\text { 1. Working place, association (only staff } \\
\text { members) }(n=23)\end{array}$ & 1 & 4 & 19 & 82 \\
2. Media: TV, radio, newspapers, etc. & 22 & 55 & 8 & 21 \\
3. Internet supplier & 5 & 12 & 12 & 31 \\
4. Public Administration & 5 & 12 & 21 & 54 \\
5. Non-profit organizations & 10 & 25 & 14 & 36 \\
6. Webpages about Internet safety & 11 & 28 & 7 & 18 \\
7. Family and friends & 15 & 37 & 2 & 5 \\
8. Other sources & 7 & 17 & 4 & 10 \\
9. No specific information or training & 4 & 10 & 3 & 8 \\
\hline
\end{tabular}

However, respondents considered that the Administration $(54 \%)$ as well as non-profit organisations $(36 \%)$ should provide this information. They also think that the Internet supplier should be a source of information (31\%). Other sources such as media $(21 \%)$, specialised webpages $(18 \%)$ or family and friends $(5 \%)$ were less preferred. Staff members also reported that they had not received training in their working place $(96 \%)$ but they chose this option as the most preferred source of information ( $82 \%)$.

Finally, only $10 \%$ of the participant caregivers had not received any specific information or training and the same percentage did not want to receive it.

Differences between family and staff members were found in three information sources. First, webpages about Internet safety $(\phi=.397, p=.013)$ with $35 \%$ of family members preferring this source of information while only $5 \%$ of staff members chose it. Second, none of the staff members chose family and friends as a source of information while $12 \%$ of the family members preferred it $(\phi=.264, p=.099)$. Third, $18 \%$ of the family members did not want any specific information or training while all of the participant staff members considered they needed information or training in Internet safety $(\phi=-397, p=.013)$.

\section{DISCUSSION AND CONCLUSIONS}

The present study provides an initial overview of family and staff members' major concerns about the use of the Internet by people with ID and how prepared they feel to address the potential risks of going online. Overall, caregivers consider that the Internet is less safe for people with ID and for children than for non-disabled adults. They are especially concerned about others using individuals with ID's personal information or being asked for information and photos, as well as being bullied or harassed, being exposed to inappropriate sexual content or being threatened. These results are similar to those found in previous research (Chadwick et al., 2017; Molin et al., 2015) and underpin the general idea that people with ID, regardless of their age, are more vulnerable to Internet risks than the rest of the population (Chadwick et al., 2017). Caregivers are usually ambivalent towards the use of the Internet by people with ID, since they think they have to protect them from potential risks, but at the same time, they want to promote their independence and self-determination by supporting them to make their own decisions. The study conducted by Molin et al. (2015) concluded that, despite caregivers' concerns about the use of the Internet by people with ID, its benefits overweigh the inconveniences. The 'positive risk-taking' approach, in the context of the Internet, stands up for the idea that people with ID should make their own decisions with respect to their life and the way they want to live it (Seale, 2014). Online risks should not be avoided or ignored, but instead acknkowledged and managed, so people with ID can have greater control of their lives and a chance to enhance their well-being. In this context, caregivers should not overprotect them but, alternatively, work on a shared decision-making and negotiation process between them and people with ID to discuss and agree on actions after considering the potential positive and negative outcomes of Internet use (McConkey \& Smyth, 2003).

To prevent some of the potential risks of going online, the present study found that caregivers usually talk with people with ID about their activities on the Internet and warn them about some specific behaviours like online chatting or flirting with strangers, misleading adverstising, and identity and data theft, among others. These prevention strategies are designed to promote the inclusion of people with ID in the digital arena in a safe and responsible way. Caregivers do not try to protect them by exerting control or avoiding the use of the Internet (e.g. only $8 \%$ of the participants forbid the use of social networks to the individuals with ID). Instead, they prefer to inform people with ID about the online risks and how to use the Internet safely. However, there is still a lack of evidence about these issues and further research is needed to learn more about the strategies professionals and parents engage to support the use of the Internet by people with ID, without leaving aside their security.

According to the results of this study, more than half of the participants do not feel prepared to prevent or cope with problems encountered on the Internet by people with ID. Most of the information they have about Internet safety comes from media or friends and family, although they prefer more formal training provided by the Administration and non-profit organisations. Staff members seemed to be more concerned about the online risks than family members. Moreover, staff members considered that they needed more information and training to be able to support people with ID adequately in the use of the Internet, while almost 
$20 \%$ of the family members thought that it was not necessary. More research is needed to explore the reasons of these differences. Is it because they think they are already well prepared to manage online risks, or is it because they are actually unaware of the potential risks of the Internet and therefore do not feel the need for training? The lack of training could lead to wrong risk perceptions from caregivers in relation to people with ID and the Internet (Seale, 2014), limiting their access to this tool. As pointed out by Löfgren-Mårtenson (2008), caregivers usually show strong feelings of responsibility, and therefore they may want to protect people with ID by exerting some kind of control. However, a better understanding of online use, risks and safety will enable caregivers to look beyond the potential negative experiences of the Internet and facilitate the access to a tool that can be highly beneficial for people with disabilities (Chadwick, Wesson, \& Fullwood, 2013). Training programmes for all the groups involved in this process (i.e. people with ID, professionals and family) should be designed, implemented and assessed.

Although the aim of this study was to examine cargivers' views about Internet risks and safety with regard to people with ID, we were unable to generalise our results to the population for two reasons. First, the sample was drawn from only one association and their responses may not represent those from other organisations. The particularities of this association may determine the perceptions staff and family members have about the issues addressed in this study. Second, the response rate was very low in the case of family members and, therefore, the overall sample was also low, not allowing us to generalise the findings to the wider population. Similar studies should be conducted with a more extensive sample which should include a greater number of participants from different organisations devoted to people with ID. Finally, although anonymity was guaranteed during the whole process of the study, participants could have provided socially desirable responses which may not reflect their actual views.

Findings in this study suggest that more attention should be paid to those who provide support to people with ID and can therefore facilitate their access to the Internet. Caregivers report a lack of formal training in Internet safety, whilst also pointing out their concerns about people with ID gaining online access. Providing them with the right strategies to identify, prevent and cope with the potential risks of the Internet will lead to a better understanding of the benefits of this technology and, therefore, to the ability to promote the responsible use of the Internet by people with ID.

\section{REFERENCES}

Auna Foundation. (2004). Las personas con discapacidad frente a las tecnologías de la information y las comunicaciones en España. Retrieved from http://www. cermi.es/es-ES/Biblioteca/Lists/Publicaciones/Attachments/36/Estudio20DiscapacidadTICFundAuna.pdf

Chadwick, D. D., Quinn, S., \& Fullwood, C. (2017). Perceptions of the risks and benefits of Internet access and use by people with intellectual disabilities. British Journal of Learning Disabilities, 45(1), 21-31. doi:10.1111/bld.12170

Chadwick, D. D., \& Wesson, C. (2016). Digital inclusion and disability. In A. Atrill \& C. Fullwood (Eds.), Applied Cyberpsychology: practical applications of cyberpsychological theory and research (pp. 1-24). Houndmills, UK: Palgrave Macmillan. doi:10.1057/9781137517036 1

Chadwick, D. D., Wesson, C., \& Fullwood, C. (2013). Internet access by people with intellectual disabilities: inequalities and opportunities. Future Internet, 5 , 376-397. doi:10.3390/fi5030376

Clarke, C. L., Lhussier, M., Minto, C., Gibb, C. E., \& Perini, T. (2005). Paradoxes, locations and the need for social coherence: a qualitative study of living with a learning difficulty. Disability \& Society, 20(4), 405-419. doi:10.1080/09687590500086534

Feng, J., Lazar, J., Kumin, L., \& Ozok, A. (2008). Computer usage by young individuals with down syndrome: an exploratory study. In S. Harper \& A. Barreto (Eds.), Proceedings of the 10th international ACM SIGACCESS conference on
Computers and accessibility (pp. 35-42). Halifax, Nova Scotia, Canada: ACM. doi:10.1145/1414471.1414480

Garmendia, M., Garitaonandia, C., \& Casado, M. A. (2011). Riesgos y seguridad en Internet: los menores españoles en el contexto europeo. Universidad del País Vasco / Euskal Herriko Unibertsitatea, Bilbao: EU Kids Online.

Jay, P. (1979). Report of the Committee Enquiry into Mental Handicap Nursing and Care. London, UK: HMSO.

Kydland, F., Molka-Danielsen, J., \& Balandin, S. (2012). Examining the use of social media tool "Flickr" for impact on loneliness for people with intellectual disaiblity. In T. Fallmyr (Ed.), NOKOBIT 2012: Proceedings of the 2012 Norsk konferanse for organisasjoners bruk av informasjonsteknologi (pp. 253-264). Trondheim, Norway: Akademika forlag. Retrieved from http://dro.deakin.edu. au/view/DU:30062177

Lawshe, C. H. (1975). A quantitative approach to content validity. Personnel Psychology, 28, 563-575. doi:10.1111/j.1744-6570.1975.tb01393.x

Livingstone, S., \& Haddon, L. (2009). EU Kids Online: Final Report. LSE, London, UK: EU Kids Online.

Luckasson, R., Bornthwick-Duffy, S., Buntinx, W., Coulter, D. L., Craig, E. M., Reeve, A., \& Tasse, M. J. (2002). Mental retardation. Definition, classification and systems os supports. Washington, DC: American Association on Mental Retardation.

Löfgren-Mårtenson, L. (2008). Love in cyberspace. Swedish young people with intellectual disabilities and the Internet. Scandinavian Journal of Disability Research, 10(2), 125-138. doi:10.1080/15017410701758005

McConkey, R., \& Smyth, M. (2003). Parental perceptions of risks with older teenagers who have severe learning difficulties contrasted with the young people's views and experiences. Children \& Society, 17(1), 18-31. doi:10.1002/chi.725

Molin, M., Sorbring, E., \& Löfgren-Martenson, L. (2015). Teachers' and parents' views on the Internet and social media usage by pupils with intellectual disablities. Journal of Intellectual Disabilities, 19(1), 22-33. doi: $10.1177 / 1744629514563558$

Näslund, R., \& Gardelli, Å. (2013). 'I know, I can, I will try': youths and adults with intellectual disabilities in Sweden using information and communication technology in their everyday life. Disability \& Society, 28(1), 28-40. doi: $10.1080 / 09687599.2012 .695528$

Orange Foundation. (2013). Informe e-España 2013. Retrieved from http://www. proyectosfundacionorange.es/docs/eEspana 2013 web.pdf

Pantoja, A., Orellana, N., Muñoz, J. M., \& Espiñeira, E. M. (2012). Brecha digital e inclusión educativa y social. In C. Jiménez Fernández, J. L. García Llamas, B. Álvarez González, \& J. Quintanal Díaz (Eds.), Investigación y educación en un mundo en red (pp. 121-150). Madrid: McGraw-Hill.

Parsons, S., Daniels, H., Porter, J., \& Robertson, C. (2008). Resources, staff beliefs and organizational culture: factors in the use of information and communication technology for adults with intellectual disabilities. Journal of Applied Research in Intellectual Disabilities, 21, 19-33.

Perske, R. (1972). The Dignity of Risk. In W. Wolfensberger, B. Nirje, S. Olansky, R. Perske, \& P. Roos (Eds.), The Principles of Normalization in Human Services (pp. 194-200). Toronto, Canada: National Institute on Mental Retardation through Leonard Crainford.

Salmerón, L., Gómez, M., \& Fajardo, I. (2016). How students with intellectual disabilities evaluate recommendations from internet forums. Reading and Writing, 29(8), 1653-1675. doi:10.1007/s11145-016-9621-4

Seale, J. (2014). The role of supporters in facilitating the use of technologies by adolescents and adults with learning disabilities: a place for positive risk-taking. European Journal of Special Needs Education, 29(2), 220-236. doi: $10.1080 / 08856257.2014 .906980$

Seale, J., Nind, M., \& Simmons, B. (2013). Transforming positive risk-taking practices: the possibilities of creativity and resilience in learning disability contexts. Scandinavian Journal of Disability Research, 15(3), 233-248. doi:10.1080/15017419.2012.703967

Valero, M. A., Vadillo, L., Herradón, R., Bermejo, A. B., \& Conde, R. (2011). Investigación sobre las tecnologías de la sociedad de la información para todos. Madrid: CENTAC

World Health Organization. (2011). World report on disability. Malta: Author.

How to cite this article: Chiner, E., Gómez, M., \& Cardona, M. C (2017). Internet and people with intellectual disability: an approach to caregivers' concerns, prevention strategies and training needs. Journal of New Approaches in Educational Research, 6(2), 153-158. doi: 10.7821/naer.2017.7.243 